\title{
Florigen and the Photoperiodic Control of Flowering in Rice
}

\author{
Hiroyuki Tsuji • Shojiro Tamaki • Reina Komiya • \\ Ko Shimamoto
}

Received: 19 May 2008 / Accepted: 25 June 2008 /Published online: 15 August 2008

(C) Springer Science + Business Media, LLC 2008

\begin{abstract}
Flowering time is a key trait for geographical and seasonal adaptation of plants and is an important consideration for rice breeders. Recently identified genetic factors provide new insights into this complex trait. The list of genes involved in flowering and their functions tells us that the molecular basis of day-length measurement includes both of the evolution of unique factors and the regulatory adaptation of conserved factors in rice. This information helped identify rice florigen, a mobile flowering signal. Our current view of flowering time regulation incorporates the presence of complex layers of gene networks integrated with the synthesis of florigen protein and its subsequent transport and perception.
\end{abstract}

Keywords Florigen $\cdot$ Flowering time $\cdot$ Genetic pathways

\section{Introduction}

Flowering time, often referred to as heading date in cereal crops, is a key agronomical determinant for adaptation to specific cropping locations and growing seasons for current varieties of cultivated rice. Developing early-flowering or photoperiod-insensitive cultivars has been a major objective of rice breeding for several decades. The molecular and developmental determinants of flowering time have thus also particularly important genetic targets for domestication or for breeding new varieties of rice. Flowering time is

\footnotetext{
H. Tsuji $\cdot$ S. Tamaki $\cdot$ R. Komiya $\cdot$ K. Shimamoto $(\bowtie)$

Laboratory of Plant Molecular Genetics,

Nara Institute of Science and Technology (NAIST),

8916-5 Takayama,

Ikoma, Nara 630-0101, Japan

e-mail: simamoto@bs.naist.jp
}

controlled by many genes, which are expressed or suppressed in close interaction with environmental factors such as day length and temperature. Progress in the molecular genetics has provided a clearer understanding of several pivotal mechanisms regulating flowering time determination in rice, and these studies have been summarized from genetic, molecular biological, or comparative biological perspectives [17, 24, 25, 43, 83]. In this review, we discuss the current understanding of rice flowering, considering the recent finding of a strong candidate for the long soughtafter mobile flowering stimulus, florigen [74].

\section{Hd3a protein as the rice florigen}

Heading date $3 a(H d 3 a)$ was first detected as a quantitative trait locus (QTL), which promotes flowering of rice under short-day (SD) conditions [55, 80]. Hd3a encodes an ortholog of Arabidopsis FLOWRING LOCUS T (FT) [38]. Overexpression of $\mathrm{Hd} 3 \mathrm{a}$ protein with the constitutive promoter [38] or vascular-specific promoters [74] results in an early-flowering phenotype, and suppression of $\mathrm{Hd} 3 \mathrm{a}$ with RNA interference (RNAi) delays flowering [39]. $\mathrm{Hd} 3 \mathrm{a}$ is a member of a large gene family consisting of at least 13 genes in rice genome [6] and at least two paralogs, Rice FLOWERING LOCUS T1 (RFT1) and FT-Like (FTL) promote flowering $[28,39]$. Hd3a/FT proteins are about $22 \mathrm{kDa}$ in size, and their overall structures are similar to mammalian phosphatidyl ethanolamine-binding proteins or Raf-kinase inhibitor proteins (RKIP) [3], although it is not known whether or not $\mathrm{Hd} 3 \mathrm{a} / \mathrm{FT}$ binds to phosphatidyl ethanolamine or inhibits kinase.

Recent progress in the molecular genetics of Arabidopsis indicates that $F T$ has a strong flowering promotion effect downstream of the known photoperiodic flowering pathway 
[17, 21, 36]. Arabidopsis flowering is promoted by long day (LD), whereas rice flowering is promoted by SD. FT is a major floral activator that is expressed in the vascular tissues of leaves under inductive LD in Arabidopsis [32, 37, 71]. FT protein interacts with the bZIP transcription factor FLOWERING LOCUS D (FD), which is only expressed in the shoot apical meristem (SAM), and this interaction seems to be necessary for full activation of FT floral promotion $[1,76]$. The anatomical separation of expression sites implies that $F T$ product is a primary candidate for florigen. If $F T$ encodes the florigen, it could act as a mobile agent either via protein or messenger RNA (mRNA), either of which could move to the SAM to interact with FD. Therefore, a major focus was whether transcripts or protein account for the mobile florigenic activity [85].

The question was answered with the introduction of rice as a paradigm for exploring the nature of florigen (Fig. 1) [74]. First, the precise sites of $H d 3 a$ transcription and mRNA accumulation were determined. The promoter activity of $H d 3 a$ was detected in transgenic plants expressing $\beta$-glucuronidase (GUS) under the control of the $H d 3 a$ promoter in the vascular cells of leaf blades. No GUS activity was detected in the SAM. This is consistent with the tissue specificity of $F T$ expression in Arabidopsis, although expression is induced by LD for $F T$ and by SD for $H d 3 a$ [32, 37]. $H d 3 a$ mRNA accumulates in leaf blades but is present at very low levels in leaf sheaths and is four orders of magnitude lower in the shoot apex than in leaf blades under SD conditions. Therefore, it is unlikely that $H d 3 a$ mRNA moves from leaves to the SAM in any significant amount. $H d 3 a$ expression is thus limited to the vascular tissues of leaf blades under SD conditions.

Secondly, the tissue localization of $\mathrm{Hd} 3$ a protein was examined using transgenic rice plants expressing Hd3aGFP fusion protein driven by the Hd3a promoter. Hd3aGFP was present in vascular tissue from the leaf blade to the upper part of the stem, the region just below the meristem where nodes are present, and in the inner conelike region of the SAM. Hd3a-GFP protein is thus synthesized in the vascular tissues of leaf blades and transported through the phloem. Hd3a protein is then unloaded from the end of the vascular tissue and enters the SAM through cells just beneath the SAM [74]. Essentially, the same localization of Hd3a-GFP was observed when other vascular-specific promoters were used to express Hd3a-GFP, confirming that Hd3a-GFP is translocated from leaf and stem vasculature to the SAM. These observations indicate that $\mathrm{Hd} 3$ a protein is a mobile flowering signal in rice (Fig. 1). The ability of Hd3a/FT protein to move long distances is also suggested from a study of the rice phloem sap proteome [4]. Rice phloem sap contains a member of Hd3a/FT protein family, FT-LIKE12, along with RKIP-like proteins RICE CENTRORADIALIS3 (RCN3) and MOTHER OF FT1. Hd3a itself was not detected, probably because photoperiod conditions and timing of sampling was not suitable for detection of $\mathrm{Hd} 3 \mathrm{a} . \mathrm{Hd} 3 \mathrm{a} / \mathrm{FT}$ proteins, however, have been detected in the phloem sap of other plant species. CmFTL2, a functional ortholog of $\mathrm{Hd} 3 \mathrm{a} / \mathrm{FT}$ in Cucurbita maxima, has also been found in vascular sap and can move through graft unions to promote flowering [47]. Phloem sap obtained from the inflorescence

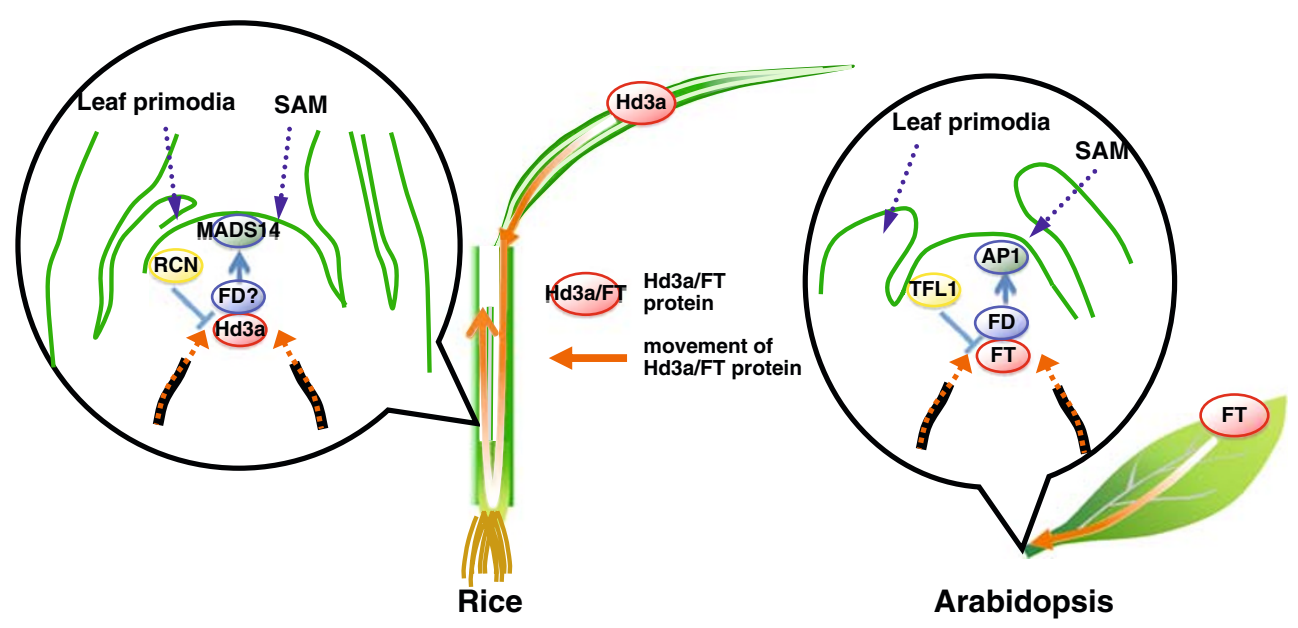

Fig. 1 Model of Hd3a/FT action in rice and Arabidopsis. Hd3a/FT protein is synthesized in the vascular tissue of the leaf and transported through phloem tissue. $\mathrm{Hd} 3 \mathrm{a} / \mathrm{FT}$ protein is unloaded from the end of the vascular tissue and enters into the SAM through the cells just

below the SAM. Several lines of evidence suggest that Hd3a/FT protein interacts with the bZIP transcription factor FD, which directly binds promoter region of floral meristem identity gene $A P 1$. Hd3a/FT is a strong candidate for florigen. 
stems of Brassica napus also contained FT protein [14]. These observations provide additional evidence that $\mathrm{Hd} 3 \mathrm{a} /$ FT proteins are florigens. Evidence from Arabidopsis also supports the florigen activity of FT protein. Phloemexpressed FT-GFP and Myc-tagged FT move to the apex and cause early flowering, but FT protein with nuclear localization signal or 3xYFP do not, probably because of immobilization [8, 29, 52].

\section{$R F T 1$ also promotes flowering in rice}

The RFT1 gene lies adjacent to $H d 3 a$, separated by only $11.5 \mathrm{~kb}$ on chromosome 6 of rice [26]. Hd3a and RFTI sequences are very similar, and they were likely produced by a recent tandem duplication event [6]. The corresponding chromosomal regions of the $H d 3 a / R F T 1$ locus in maize or wheat contain only a single $H d 3 a$ ortholog [ 10 , 82]. RFT1 tissue-specific expression is similar to that of $H d 3 a$ in that it is expressed in vascular tissues of leaf blades in response to SD. Thus, RFT1 could possibly function redundantly with $H d 3 a$ in promoting rice flowering as another florigen. The interesting involvement of RFT1 was revealed from a detailed analysis of rice plants with RNAi-suppressed $H d 3 a$ expression [39]. Flowering of $H d 3 a$ RNAi plants was delayed by more than 30 days under SD conditions. Although flowering of RFT1 RNAi plants was normal, suggesting that RFT1 does not on its own promote flowering under SD conditions, double RNAi plants in which both $H d 3 a$ and $R F T 1$ are suppressed did not flower up to 300 days after germination. Both $H d 3 a$ and RFT1 are thus involved in the normal regulation of flowering in rice. RFT1 expression is normally low in wild-type rice plants but is up-regulated in $H d 3 a$ RNAi plants and is correlated with reproductive transition of the SAM. This up-regulation is also correlated with an increase of histone-3-acetylation of nucleosomes around the transcription initiation site of RFT1. These results suggest that $R F T 1$ expression increases in the absence of $\mathrm{Hd} 3 \mathrm{a}$ and that RFT1 complements $H d 3 a$ function [39]. RFT1 thus serves as another flowering promotion activity in rice under certain conditions.

\section{Hd3a/FT signaling in the shoot apical meristem}

The identification of Hd3a/FT as florigen opens the door to studying the molecular mechanism(s) of $\mathrm{Hd} 3 \mathrm{a} / \mathrm{FT}$ signaling in the SAM. The current understanding of events downstream of $\mathrm{Hd} 3 \mathrm{a} / \mathrm{FT}$ activity focuses on FD, MADS-box transcription factors, and CENTRORADIALIS (CEN) / TERMINAL FLOWER1 (TFL1). Corresponding genes of the proteins discussed below are summarized in Table 1.
FD

In the SAM, Hd3a may interact with a bZIP transcription factor orthologous to Arabidopsis FD to induce phase transition from vegetative to reproductive states. In Arabidopsis, $F D$ is expressed on the flanks of the SAM where flower primordia are initiated. $F D$ is expressed during the vegetative phase so that it is present when FT arrives. In the presence of FT, FD induces the floral meristem identity gene APETALA1 (AP1) and its paralog FRUITFULL (FUL) $[2,76]$. At present, there are no reports describing FD function in rice, whereas the maize late flowering mutant delayed flowering 1 (dlfl) provides a hint about FD function in rice and other cereals [58]. The DLF1 gene encodes an ortholog of $F D$. Loss-of-function mutants of maize $D L F 1$ (dlf1) have a late flowering phenotype with some abnormal tassel branches. The most abundant DLF1 expression is found in the SAM, and it peaks during vegetative-to-reproductive phase transition, decreasing gradually during inflorescence development. DLF1 has also been shown to interact with maize $\mathrm{Hd} 3 \mathrm{a} / \mathrm{FT}$. The maize genome contains at least 15 members of the $H d 3 a / F T$ gene family. Two of them, Zea mays CENTRORADIALIS $8(Z C N 8)$ and ZCN14, interact with DLF1 in yeast twohybrid assays [10]. ZCN8 transcripts are present in leaf blades before floral transition, increases just before floral transition, and stays high afterward. Because of its expression pattern and interaction with DLF1, ZCN8 should be considered as a florigen candidate in maize. ZCN15, an ortholog of rice $H d 3 a$, which resides in the syntenic chromosome region of rice $H d 3 a$, is weakly expressed in leaf blades after phase transition and relatively highly expressed in the developing kernel. The activation of AP1 by $\mathrm{Hd} 3 \mathrm{a} / \mathrm{FT}$ and FD is operative in cereal crops. The dlf1 mutation of maize delayed the expression of maize AP1/ FUL MADS-box gene ZMM4, an ortholog of OsMADS14/ $R A P 1 B$, in the SAM [11], and TaFDL2, a wheat FD homolog, can interact with wheat FT protein VERNALIZA TION3 (VRN3)/TaFT and directly binds the promoter region of wheat $A P 1$ homologous gene in vitro [45].

There are at least seven orthologs of $F D$ in the rice genome [60]. OsbZIP24 mRNA is relatively abundant in the SAM, and OsbZIP54 mRNA is distributed throughout the rice plant, including the SAM, whereas transcript accumulation of other FD-like bZIPs is below the microarray detection limit [60]. It is yet to be determined if there is some unresolved functional differentiation among these FD-like proteins of rice.

MADS-box transcription factors

The gene network, which acts downstream of FT in the SAM, involves MADS-box genes in Arabidopsis. Both FT 
Table 1 Genes that are Expected to be Involved in Hd3a/FT Signaling in SAM

\begin{tabular}{|c|c|c|c|c|c|c|}
\hline Category & Gene name & Accession no. & Organism & Domain & Function & Reference \\
\hline \multirow[t]{8}{*}{$\mathrm{Hd} 3 \mathrm{a} / \mathrm{FT}$} & $H d 3 a$ & Os06g0157700 & Rice & \multirow[t]{8}{*}{ Raf-kinase inhibitor } & $\begin{array}{l}\text { Florigen; promotion } \\
\text { of flowering }\end{array}$ & {$[38]$} \\
\hline & $R F T$ & Os06g0157500 & Rice & & Promotion of flowering & {$[28]$} \\
\hline & $F T L$ & Os01g0218500 & Rice & & Promotion of flowering & {$[28]$} \\
\hline & ZCN8 & EU241924 & Maize & & n.d. & {$[11]$} \\
\hline & ZCN15 & EU241930 & Maize & & n.d. & [11] \\
\hline & $V R N 3 / T a F T$ & DQ890165 & Wheat & & Promotion of flowering & [82] \\
\hline & $F T$ & At1g65480 & Arabidopsis & & $\begin{array}{l}\text { Florigen; Promotion } \\
\text { of flowering }\end{array}$ & {$[32,37]$} \\
\hline & $T S F$ & AT4g20370 & Arabidopsis & & Promotion of flowering & [78] \\
\hline \multirow[t]{5}{*}{ CEN/TFL1 } & $R C N 1$ & Os11g0152500 & Rice & \multirow[t]{5}{*}{ Raf-kinase inhibitor } & Inhibition of flowering & [59] \\
\hline & RCN2 & Os02g0531600 & Rice & & Inhibition of flowering & [59] \\
\hline & $R C N 3$ & Os12g0152000 & Rice & & Inhibition of flowering & {$[59,87]$} \\
\hline & OsCEN3 & Os04g0411400 & Rice & & n.d. & [87] \\
\hline & TFL1 & At5g03840 & Arabidopsis & & Inhibition of flowering & {$[5]$} \\
\hline \multirow[t]{10}{*}{ FD } & OsbZIP24 & Os02g0833600 & Rice & \multirow[t]{10}{*}{ bZIP } & n.d. & {$[60]$} \\
\hline & OsbZIP27 & Os03g0306700 & Rice & & n.d. & {$[60]$} \\
\hline & OsbZIP54 & Os06g0719500 & Rice & & n.d. & {$[60]$} \\
\hline & OsbZIP55 & Os06g0720900 & Rice & & n.d. & {$[60]$} \\
\hline & OsbZIP56 & Os06g0724000 & Rice & & n.d. & {$[60]$} \\
\hline & OsbZIP69 & Os08g0549600 & Rice & & n.d. & {$[60]$} \\
\hline & OsbZIP77 & Os09g0540800 & Rice & & n.d. & {$[60]$} \\
\hline & $D L F 1$ & EF093789 & Maize & & Promotion of flowering & {$[58]$} \\
\hline & TaFDL2 & EU307112 & Wheat & & n.d. & [45] \\
\hline & $F D$ & At4g35900 & Arabidopsis & & Promotion of flowering & {$[1,76]$} \\
\hline \multirow{7}{*}{$\begin{array}{l}\text { MADS-box transcription } \\
\text { factor (FUL/AP1/CAL) }\end{array}$} & OsMADS14/RAP1B & Os03g0752800 & Rice & \multirow[t]{7}{*}{ MADS-box } & Promotion of flowering & {$[41]$} \\
\hline & OsMADS15/RAP1A & Os07g0108900 & Rice & & n.d. & [41] \\
\hline & ZMM4 & AJ430641 & Maize & & Promotion of flowering & {$[11]$} \\
\hline & $W A P 1 / V R N 1$ & AB007504/AY188331 & Wheat & & Promotion of flowering & {$[56,81]$} \\
\hline & $F U L$ & At5g60910 & Arabidopsis & & Promotion of flowering & {$[15]$} \\
\hline & $A P 1$ & At1g69120 & Arabidopsis & & n.d. & {$[51]$} \\
\hline & $C A L$ & At1g26310 & Arabidopsis & & n.d. & [33] \\
\hline \multirow{2}{*}{$\begin{array}{l}\text { MADS-box transcription } \\
\text { factor (SOC1) }\end{array}$} & OsMADS50/OsSOC1 & Os03g0122600 & Rice & \multirow[t]{2}{*}{ MADS-box } & Promotion of flowering & [44] \\
\hline & SOC1 & At2g45660 & Arabidopsis & & Promotion of flowering & {$[65]$} \\
\hline
\end{tabular}

n.d. Not functionally determined yet

and FD, together with LEAFY, are required for inducing expression of $A P 1$ and $F U L$ in the SAM $[2,53,75]$. FTdependent gene regulation is also observed in Arabidopsis leaves. Expression of FUL and SEPALATA3 was induced in leaves overexpressing $F T$ and was reduced in $f t$ and $f d$ mutants [75]. Thus, leaves and the SAM may share similar regulatory mechanisms. In rice, the expression of OSMADS14/RAP1B, an ortholog of AP1, and OSMADS15/ $R A P 1 A$ are up-regulated by $H d 3 a$ in leaf blades under SD conditions [39], suggesting that the same regulatory network is involved in the SAM of rice. OsMADS14/RAP1B is expressed in the SAM during the reproductive phase [13, 41], and its ectopic expression strongly promotes rice flowering [31]. Interestingly, a mutant of the OSMADS14/ $R A P 1 B$ ortholog in einkorn wheat (Triticum monococcum), maintained vegetative phase ( $m v p$ ), cannot show transition from vegetative to reproductive phases [67]. The $m v p$ phenotype is caused by a deletion of the promoter and coding region of Wheat AP1 (WAP1)/VERNALIZATION1 (VRN1), a gene that lies within the wheat chromosome region corresponding to the region containing OSMADS14/ $R A P 1 B$ in rice [81]. Reduced levels of $V R N 3 / T a F T$, an ortholog of rice $H d 3 a$, are associated with lower levels of VRN1 transcripts, consistent with the observation in rice [82]. Although AP1 in Arabidopsis is unlikely to be the FT target in the SAM for flowering control because ap1 mutants are not late flowering [62], AP1 MADS-box proteins are likely to function as important mediators of $\mathrm{Hd} 3 \mathrm{a} / \mathrm{FT}$ activity in flowering of cereals. OsMADS14/RAP1B is also an activator of $H d 3 a$ expression in leaves [34, 43]. Consistent with this, reduced levels of $V R N 1$ are also correlated with reduced levels of $V R N 3$ in barley [20]. 
Suppressor of Overexpression of Constans1 (SOC1) in Arabidopsis is a MADS-box protein, and a recent genetic study suggests that FT mediates the activation of SOC1 downstream of CONSTANS (CO) [44]. SOC1 directly interacts with AGAMOUS-LIKE24 (AGL24) MADS-box protein in the shoot apex, and direct binding of the SOC1AGL24 complex to the promoters of both SOC1 and $A G L 24$ upregulates their expression [48]. On the other hand, the regulatory hierarchy and the site of action seem to be different in rice; a T-DNA insertion mutation of OsMADS50/OsSOC1 results in a reduction of $\mathrm{Hd} 3 \mathrm{a}$ transcription in leaves, whereas RNAi suppression of $H d 3 a$ or of both $H d 3 a$ and RFT1 does not result in any change in OsMADS50/OsSOC1 expression. Thus, in rice, OsMADS50/OsSOCl acts upstream of $\mathrm{Hd} 3 \mathrm{a}$ expression in leaf blades [39, 44].

\section{CEN/TFL1}

CENTRORADIALIS (CEN)/TERMINAL FLOWER1 (TFL1) proteins provide interesting insights into $\mathrm{Hd} 3 \mathrm{a} /$ FT signaling in the SAM. CEN/TFL1 are homologs of $H d 3 a / F T$ and encode RKIP proteins, but CEN/TFL1 proteins repress flowering. Arabidopsis TFL1 mRNA is limited to the central cells of the inflorescence shoot meristem, and the TFL1 protein migrates to outer cells [7]. Repression of flowering has been thoroughly investigated using Arabidopsis FT and TFL1 [3, 16]. Proteins carrying replacements of individual residues or specific regions of FT and TFL1 were overexpressed in a ft tfll double mutant to map the residues or regions that confer specific activity on the two proteins. The crystal structures of FT and TFL1 were also compared to map the region of specificity. These analyses suggest that His 88 in TFL1 and the corresponding Tyr85 in FT are important for the opposite activities of FT and TFL1 [16] and that the region responsible for the difference is localized in a 14 amino acid segment in the external loop at the C-termini of the proteins [3].

There are at least four CEN/TFL1-like genes in the rice genome [6]. RICE CENTRORADIALS1 (RCN1), RCN2, and $R C N 3 /$ Oscen 1 are able to delay flowering and affect panicle architecture when overexpressed [59, 87]. Interestingly, $\mathrm{RCN} 3$ protein can be detected in the phloem sap of rice, suggesting that this protein signals to communicate between distant organs, much like Hd3a [4]. An attractive hypothesis to explain the difference between $\mathrm{Hd} 3 \mathrm{a} / \mathrm{FT}$ and CEN/TFL1 regulatory activity is that the external loops bring different partners to $\mathrm{Hd} 3 \mathrm{a} / \mathrm{FT}$ or CEN/TFL1, thus defining the function of the complex. Screening for interacting proteins using specific external loop regions may provide further insights into $\mathrm{Hd} 3 \mathrm{a} / \mathrm{FT}$ signaling for floral promotion.

\section{Molecular-genetic pathways of the photoperiodic flowering in rice}

From an understanding of the molecular nature of Hd3a/FT proteins, it can be inferred that the timing of rice flowering is basically determined by the expression levels of the two essential flowering promotion genes, $H d 3 a$ and RFT1 in leaf blades, and by the competency of the SAM for Hd3a/ FT activity. Recent molecular genetic studies provide important insights into the day-length regulation of $\mathrm{Hd} 3 \mathrm{a}$ expression. The crucial aspect of this regulation is SD induction and LD repression of $H d 3 a$ (Fig. 2).

\section{Short-day promotion of Hd3a expression}

Under SD conditions, Hd3a expression is induced gradually and peaks at about 30 days before flowering, about the time floral transition occurs [39]. The diurnal peak of $H d 3 a$ promoter activity and mRNA accumulation coincide at dawn, suggesting the major point of $H d 3 a$ regulation is transcriptional $[23,38,74]$. The most important factors for this $H d 3 a$ expression are Heading datel (Hdl) and Early heading datel (Ehd1, see below) [24]. Hdl was first detected as the major photoperiod-sensitivity QTL, and it encodes a B-box zinc finger protein with a C-terminal CCT (CONSTANS, CONSTANS-LIKE and TIMING OF CAB EXPRESSION1) domain [84]. Under SD conditions, lossof-function alleles of $\mathrm{Hdl}$ delay flowering and reduce $\mathrm{Hd} 3 \mathrm{a}$ mRNA accumulation [23, 28, 38, 84]. Detailed phylogenetic analyses showed that $H d l$ is the sole ortholog of Arabidopsis CONSTANS (CO), which is also an important activator of FT [26]. Arabidopsis $C O$ is expressed in leaf phloem tissues [71], and $\mathrm{CO}$ protein seems to directly regulate $F T$ and its paralog TWIN SISTER OF FT (TSF) because both $F T$ and TSF are up-regulated by dexamethasone-induced activation of $\mathrm{CO}$ in the presence of the translation inhibitor cycloheximide [65, 78]. Whether Hd1 directly regulates $H d 3 a$ transcription is not clear, but differences in the temporal patterns of $H d l$ and $H d 3 a$ mRNA accumulation suggest the involvement of a somewhat more complex regulatory mechanism. $H d 1$ mRNA levels peak at midnight, but $H d 3 a$ mRNA levels peak about 4-6 h after $H d 11$ [19, 23, 28].

In addition to transcriptional regulation, $\mathrm{Hd} 1$ activity may be regulated by protein stability because Arabidopsis $\mathrm{CO}$ is subject to the regulation at the protein accumulation level. CO protein is destabilized in darkness by CONSTITUTIVELY PHOTOMORPHOGENIC1, which is counteracted by the blue-light photoreceptor CRYPTOCHROME. A PhyB-mediated signal also destabilizes $\mathrm{CO}$ at dawn [30, 42, 49].

Phytochromes also affect the expression of $\mathrm{Hd} 3 \mathrm{a}$ under $\mathrm{SD}$ conditions. $\mathrm{Hd} 3 \mathrm{a}$ expression under SD conditions is 
Fig. 2 Regulatory network of rice flowering time. Under short-day conditions, $\mathrm{Hd} 3 \mathrm{a}$ is mainly up-regulated by $\mathrm{Hd} 1$ and Ehd1. $H d 1$ is up-regulated by OsGI, and Ehdl is up-regulated by OsMADS51, whose expression is up-regulated by OsGI. $O s G I$ is regulated by the circadian clock. Under long-day conditions, Hd1 function is converted to repress $H d 3 a$ in response to a signal from phytochrome. Ehdl is repressed by Ghd7, a regulatory component that is up-regulated under longday conditions, resulting in $H d 3 a$ repression. SD or $\mathrm{LD}$ in parentheses indicate short-dayor long-day-specific regulation, respectively.

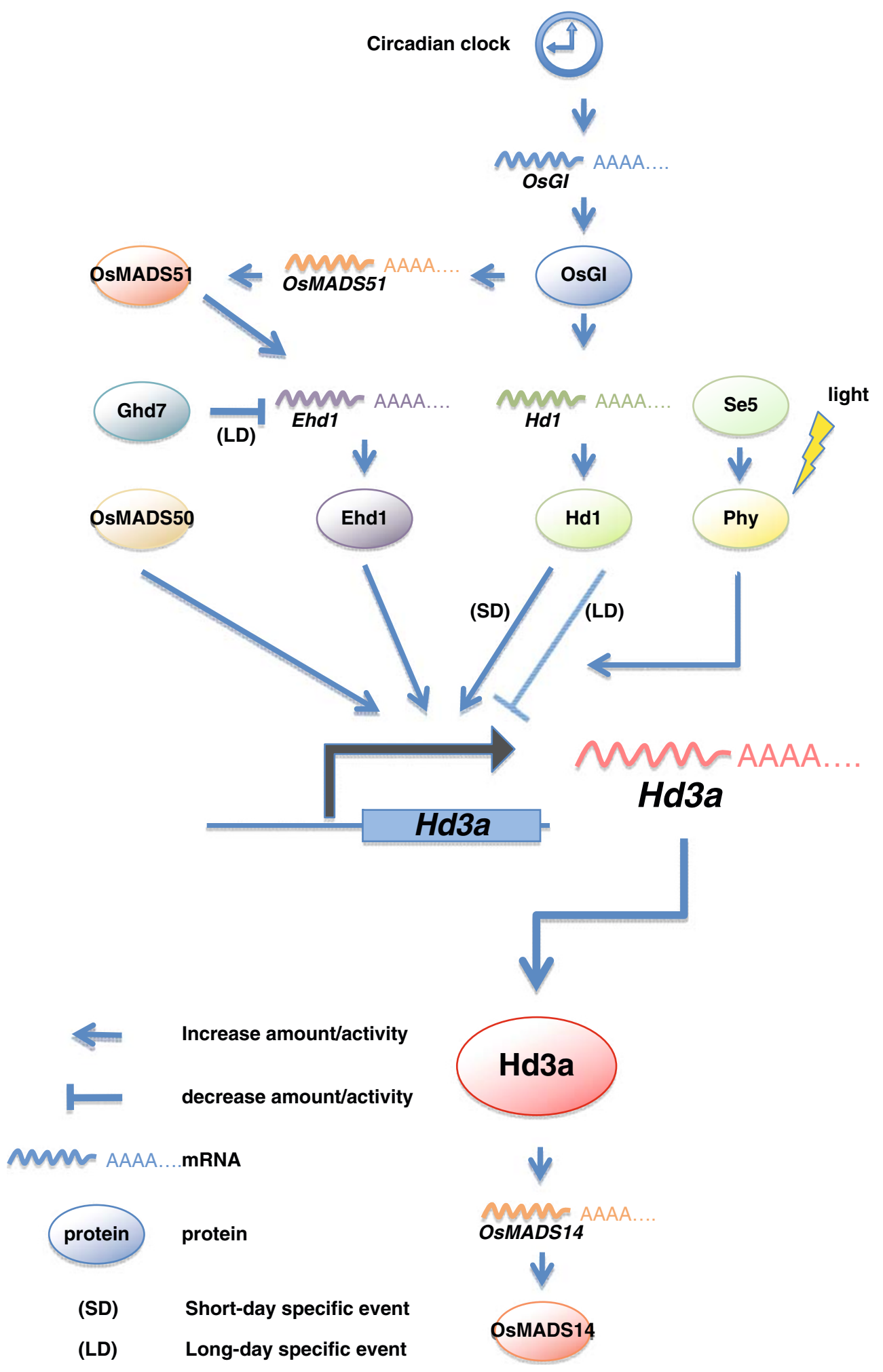

significantly up-regulated in an early-flowering photoperiodic sensitivity 5 (se5) mutant, which has a mutation in the gene encoding heme oxygenase, which is required for phytochrome chromophore biogenesis [27, 28]. Flowering under SD conditions is also promoted in phyB mutants that have loss-of-function alleles in one of the three rice phytochromes[73]. Hdl expression is not affected by se5 or phyB mutations [23, 28]; thus, phytochrome represses $\mathrm{Hd} 3 \mathrm{a}$ expression downstream or independent of $\mathrm{Hdl}$ expression under SD conditions. These phytochrome 
effects may be reminiscent of the activator-to-repressor conversion of a subset of $\mathrm{Hdl}$ proteins that is observed under LD (see below; Izawa et al. [28]).

The primary upstream regulator of $H d l$ expression is OsGI, an ortholog of GIGANTEA (GI) in Arabidopsis [18]. OsGI is a large protein that is present in both the nucleus and cytosol of rice cells [1]. Suppression of $O s G I$ expression by RNAi or antisense expression caused late flowering and reduced $H d 1 \mathrm{mRNA}$ accumulation under SD conditions [19, 34]. Arabidopsis GI plays important roles in $C O$ expression through the degradation of a repressor of $C O$ transcription $[22,66]$. Thus, it is possible that OsGI is part of a similar mechanism in rice, even though the peak in $O s G I$ expression at dusk is quite different from the $H d 1$ expression peak at midnight, suggesting the intervention of an unknown mechanism, which caused the difference in timing of expression.

OsGI expression shows circadian daily oscillation, implying upstream regulation by the circadian clock [18]. Circadian clock mutants of Arabidopsis have aberrant GI expression [54, 61], and GI itself is also considered to be a clock-associated protein $[35,50,86]$.

Another major $H d 3 a$ activator, Ehd1, was identified from a QTL of a cross between the cultivar T65 and Nipponbare [12]. Ehdl encodes a B-type response regulator, and a functional mutation is found in the GARP (maize GOLDEN2, the ARR B-class proteins from Arabidopsis, and Chlamydomonas Psrl) domain, which decreased affinity to the target DNA sequence. Mutations or RNAi suppression of Ehdl decreased $H d 3 a$ expression under SD conditions, indicating that Ehdl is the upstream regulator of $H d 3 a$ expression $[12,34]$. Ehd1 is preferentially expressed under SD conditions, peaking twice, before and after dawn, and $H d 3 a$ expression is essentially the same as Ehdl in the absence of functional $H d 1$ [12].

Ehdl is regulated by at least two factors, OsMADS51 and $G h d 7$ (for grain number, plant height, and heading date 7) $[34,77]$. OsMADS51 acts as the activator of Ehd1 expression under both SD and LD, while Ghd7 mainly acts as a suppressor of Ehdl under LD (see below). An osmads 51 T-DNA insertion mutation reduced Ehdl expression under both SD and LD. OsMADS51 expression is also up-regulated by $O s G I$ because $O S G I$ antisense repression reduced OsMADS51 and Ehdl expression. OsGI and OsMADS51 show similar daily expression oscillation, peaking at dusk in SD.

\section{Long-day suppression of $\mathrm{Hd} 3 \mathrm{a}$ expression}

Under LD conditions, $H d 3 a$ expression is very low in any developmental stage [39]. Diurnal expression is also lower than under inductive SD conditions [38]. Hd1 also has an important role in this suppression, although it works as activator of $\mathrm{Hd} 3 \mathrm{a}$ expression under SD. Before the molecular cloning of $H d 1$, it was demonstrated that nearisogenic lines containing $h d l$ mutant alleles exhibited not only delayed flowering under SD conditions but also early flowering under LD conditions, indicating that Hd1 could repress flowering under $\mathrm{LD}$ and that $\mathrm{Hdl}$ function is modified depending on day length [46]. Phytochrome signaling affects this day-length-dependent conversion of Hd1 activity because this conversion is not observed in the phytochrome-deficient mutant; flowering of the double mutant se5 hdl (which lacks both phytochrome and functional $H d 1$ ) was slightly later than that of the se5 single mutant (which lacks only phytochrome) [28]. Consistent with this observation, $H d 3 a$ mRNA accumulation is lower in se5 hdl than in se 5 mutant lines. The involvement of functional modification of $\mathrm{Hd} 1$ by day length is further supported by the direct manipulation of OsGI expression and the resulting change in $\mathrm{Hdl}$ and $\mathrm{Hd} 3 \mathrm{a}$ expression levels [19]. Overexpression of $O s G I$ delays flowering under both $\mathrm{SD}$ and $\mathrm{LD}$, indicating that $O s G I$ can act as a suppressor of flowering signals when it is constitutively expressed. In $O s G I$ overexpressing plants, Hd1 mRNA levels increase under both SD and LD, whereas $H d 3 a$ mRNA levels are negatively correlated with $H d 1$ mRNA, indicating that $H d 1$ can act as a suppressor of $H d 3 a$ when it is highly induced by $O s G I$ constitutive expression. OsGI overexpression could also be expected to increase $H d 3 a$ expression through Ehdl up-regulation by the $O s G I-$ OsMADS51 pathway (see above, Kim et al. [34]), but this effect was not observed, probably because of strong Hd1 suppressive activity. A comparison of daily temporal expression patterns of $H d l$ and $H d 3 a$ indicate that higher expression levels of $\mathrm{Hdl}$ during light periods might suppress $H d 3 a$. Under SD conditions, wild-type $H d 1$ expression starts to increase at the beginning of the dark period, thus keeping Hd1 as an activator. $O s G I$ overexpressors, however, express a significant level of $H d l$ during light periods, thus converting $\mathrm{Hd} 1$ into a repressor. Under LD, wild-type $\mathrm{Hdl}$ expression starts to increase in the light, resulting in the conversion of Hd1 into a suppressor [19]. Thus, the external coincidence model could be applied to rice: Circadian clockregulated $H d 1$ expression and an external light signal mediated by phytochrome generate the specific response to day length [25].

The repressor function of $\mathrm{Hdl}$ is not observed in connection with Arabidopsis CO, indicating that there is a different mechanism that provides this function. The photoperiod-sensitivity QTL $H d 2$ may provide information for understanding this mechanism. $H d 2$ is detected as a QTL in crosses between japonica cultivar Nipponbare and indica cultivar Kasalath [80]. A functional allele of $H d 1$ is required for Nipponbare allele of $\mathrm{Hd} 2$ to delay flowering in response to LD [46]. In addition, this $H d 2$ allele is required 
for Hd6, another photoperiod-sensitivity QTL, to delay flowering under LD [79]. Map-based cloning of this QTL revealed that it encodes an $\alpha$-subunit of casein kinase II $(\mathrm{CK} 2 \alpha)$ [72]. Plant CK2 is composed of two catalytic $(\alpha)$ subunits and two regulatory ( $\beta$ ) subunits. CK2 $\alpha$ is mainly localized in nucleus in maize [64], and several nuclear proteins are identified as substrates of CK $2 \alpha$ in maize and barley $[40,68]$, suggesting that rice Hd6 also functions in nucleus. In Arabidopsis, CK2 activity affects the timing of floral transition through phosphorylation of CIRCADIAN CLOCK ASSOCIATED1 (CCA1) and LATE ELONGATED HYPOCOTYL (LHY) proteins, which are the components of central oscillators of plant circadian clock $[9,63$, $69,70]$. Thus, the functional interaction between rice LHY and Hd6 will be an interesting issue. Rice genome contains a single ortholog of CCAI and $L H Y, O S L H Y$ [26]. When overexpressed in Arabidopsis, both OsLHY and Arabidosps CCA1 delay flowering. However, OsLHY overexpression showed only subtle effect on the rhythmic expression of PRR1 compared with the dramatic effect of CCA1 overexpression, suggesting functional difference between them [57].

Ehdl expression is suppressed under LD, which also results in reduced Hd3a expression. Ghd7 is responsible for the suppression of Ehd1 [77]. Ghd7 protein contains a CCT domain with about $60 \%$ identity to Hd1, but Ghd7 lacks the zinc finger motif, which is present in Hd1. Ghd7 expression is significantly higher under LD in leaf vascular tissue, and its diurnal expression peaks at dusk. Ghd7 expression does not affect $H d 1$ expression, but it strongly suppresses Ehdl.

\section{Night-break suppression of Hd3a expression}

A short light exposure during the dark period can significantly delay flowering of SD plants. This night-break effect has long been discussed in the context of day-length measurement in SD plants, but detailed understanding of the molecular mechanism of night break has been very limited. Like other SD plants, rice shows significant response to night break [23]. Night break suppresses $H d 3 a$ at the transcription level without affecting the expression patterns of $H d l$ and OsGI. The effect of illumination varies depending on its timing within the dark period. The night-break effect is most significant in the middle of the dark period. This night-break effect dependence on timing is correlated with the expression pattern of $H d 1$. Because $H d 3 a$ expression is mainly governed by the activity of $H d l$ and $E h d 1$, the night-break signal may affect both of the activities, which repress $H d 3 a$ transcription. The night-break effect on $H d 3 a$ expression was abolished by mutations of $p h y B$, thus the night-break signal is mediated by phyB, which probably acts via the activities of $\mathrm{Hd} 1$ and Ehd1 [23].

\section{Perspectives}

Research on flowering time regulation in rice expands the field of mobile molecular signaling in plants. Florigen is also referred to as a flowering hormone because of its mobile nature and the universality of its flowering promotion activity. Using the analogy of the canonical plant hormone studies, the next step in florigen research would be understanding $\mathrm{Hd} 3 \mathrm{a} / \mathrm{FT}$ synthesis, transport, identification of receptors, and subsequent cellular signaling. Virtually nothing is known about Hd3a long-distance trafficking. How Hd3a in companion cells is transferred to sieve element systems, how the direction of movement in phloem is determined, and how Hd3a targets the SAM after unloading from the upper end of the phloem are all open questions. Flowering time research has also identified many important genes as resources for breeding. The genetic basis of natural variation or artificial selection in flowering time genes, including genes that are or were lost through the process of domestication, should contribute not only to a further understanding of the mechanism of flowering but also to future breeding applications.

Acknowledgements We thank the members of our laboratory for helpful comments or other assistance. The work described is supported by Grants-in-Aid for Scientific Research on Priority Areas (grant 10182102 and 19090013) of the Ministry of Education, Culture, Sports, Science, and Technology of Japan (to K.S.).

\section{References}

1. Abe M, Fujiwara M, Kurotani K, Yokoi S, Shimamoto K. Identification of dynamin as an interactor of rice GIGANTEA by tandem affinity purification (TAP). Plant Cell Physiol. 2008;49:420-32.

2. Abe M, Kobayashi Y, Yamamoto S, Daimon Y, Yamaguchi A, Ikeda Y, Ichinoki H, Notaguchi M, Goto K, Araki T. FD, a bZIP protein mediating signals from the floral pathway integrator FT at the shoot apex. Science 2005;309:1052-6.

3. Ahn JH, Miller D, Winter VJ, Banfield MJ, Lee JH, Yoo SY, Henz SR, Brady RL, Weigel D. A divergent external loop confers antagonistic activity on floral regulators FT and TFL1. EMBO J. 2006;25:605-14.

4. Aki T, Shigyo M, Nakano R, Yoneyama T, Yanagisawa S. Nano scale proteomics revealed the presence of regulatory proteins including three FT-like proteins in Phloem and Xylem saps from rice. Plant Cell Physiol. 2008;49:767-90.

5. Bradley D, Ratcliffe O, Vincent C, Carpenter R, Coen E. Inflorescence commitment and architecture in Arabidopsis. Science. 1997;275:80-3.

6. Chardon F, Damerval C. Phylogenomic analysis of the PEBP gene family in cereals. J Mol Evol. 2005;61:579-90.

7. Conti L, Bradley D. TERMINAL FLOWER1 is a mobile signal controlling Arabidopsis architecture. Plant Cell. 2007;19:767-78.

8. Corbesier L, Vincent C, Jang S, Fornara F, Fan Q, Searle I, Giakountis A, Farrona S, Gissot L, Turnbull C, Coupland G. FT protein movement contributes to long-distance signaling in floral induction of Arabidopsis. Science. 2007;316:1030-3. 
9. Daniel X, Sugano S, Tobin EM. CK2 phosphorylation of CCA1 is necessary for its circadian oscillator function in Arabidopsis. Proc Natl Acad Sci USA. 2004;101:3292-7.

10. Danilevskaya ON, Meng X, Hou ZL, Ananiev EV, Simmons CR. A genomic and expression compendium of the expanded PEBP gene family from maize. Plant Physiol. 2007;146:250-64.

11. Danilveskaya ON, Meng X, Selinger DA, Deschamps S, Hermon P, Vansant G, Gupta R, Ananiev EV, Muszynski MG. Involvement of the MADS-box gene ZMM4 in floral induction and inflorescence development in Zea mays. Plant Physiol. 2008. doi:10.1104/ pp.107.115261.

12. Doi K, Izawa T, Fuse T, Yamanouchi U, Kubo T, Shimatani Z, Yano M, Yoshimura A. Ehd1, a B-type response regulator in rice, confers short-day promotion of flowering and controls FT-like gene expression independently of Hd11. Genes Dev. 2004;18:926-36.

13. Furutani I, Sukegawa S, Kyozuka J. Genome-wide analysis of spatial and temporal gene expression in rice panicle development. Plant J. 2006;46:503-11.

14. Giavalisco P, Kapitza K, Kolasa A, Buhtz A, Kehr J. Towards the proteome of Brassica napus phloem sap. Proteomics. 2006;6:896909.

15. Gu Q, Ferrándiz C, Yanofsky MF, Martienssen R. The FRUITFULL MADS-box gene mediates cell differentiation during Arabidopsis fruit development. Development. 1998;125:1509-17.

16. Hanzawa Y, Money T, Bradley D. A single amino acid converts a repressor to an activator of flowering. Proc Natl Acad Sci USA. 2005;102:7748-53.

17. Hayama R, Coupland G. The molecular basis of diversity in the photoperiodic flowering responses of Arabidopsis and rice. Plant Physiol. 2004;135:677-84.

18. Hayama R, Izawa T, Shimamoto K. Isolation of rice genes possibly involved in the photoperiodic control of flowering by a fluorescent differential display method. Plant Cell Physiol. 2002;43:494-504.

19. Hayama R, Yokoi S, Tamaki S, Yano M, Shimamoto K. Adaptation of photoperiodic control pathways produces shortday flowering in rice. Nature. 2003;422:719-22.

20. Hemming MN, Peacock WJ, Dennis ES, Trevaskis B. Lowtemperature and daylength cues are integrated to regulate FLOWERING LOCUS T in barley. Plant Physiol. 2008;14:35566.

21. Imaizumi T, Kay SA. Photoperiodic control of flowering: not only by coincidence. Trends Plant Sci. 2006;11:550-8.

22. Imaizumi T, Schultz TF, Harmon FG, Ho LA, Kay SA. FKF1FBOX protein mediates cyclic degradation of a repressor of CONSTANS in Arabidopsis. Science. 2005;309:293-7.

23. Ishikawa R, Tamaki S, Yokoi S, Inagaki N, Shinomura T, Takano M, Shimamoto K. Suppression of the floral activator Hd3a is the principal cause of the night break effect in rice. Plant Cell. 2005; 17:3326-36.

24. Izawa T. Daylength measurements by rice plants in photoperiodic short-day flowering. Int Rev Cytol. 2007a;256:191-222.

25. Izawa $T$. Adaptation of flowering-time by natural and artificial selection in Arabidopsis and rice. J Exp Bot. 2007b;58:3091-7.

26. Izawa T, Takahashi Y, Yano M. Comparative biology comes into bloom: genomic and genetic comparison of flowering pathways in rice and Arabidopsis. Curr Opin Plant Biol 2003;6:113-20.

27. Izawa $T$, Oikawa $T$, Tokutomi $S$, Okuno $K$, Shimamoto $K$. Phytochromes confer the photoperiodic control of flowering in rice (a short-day plant). Plant J. 2000;22:391-9.

28. Izawa $T$, Oikawa $T$, Sugiyama $N$, Tanisaka $T$, Yano $M$, Shimamoto K. Phytochrome mediates the external light signal to repress FT orthologs in photoperiodic flowering of rice. Genes Dev. 2002;16:2006-20.

29. Jaeger KE, Wigge PA. FT protein acts as a long-range signal in Arabidopsis. Curr Biol. 2007;17:1050-4.
30. Jang S, Marchal V, Panigrahi KCS, Wenkel S, Soppe W, Deng XW, Valverde F, Coupland G. Arabidopsis COP1 shapes the temporal pattern of $\mathrm{CO}$ accumulation conferring a photoperiodic flowering response. EMBO J. 2008;27:1277-88.

31. Jeon JS, Lee S, Jung KH, Yang WS, Yi GH, Oh BG, An GH. Production of transgenic rice plants showing reduced heading date and plant height by ectopic expression of rice MADS-box genes. Mol Breed. 2000;6:581-92.

32. Kardailsky I, Shukla VK, Ahn JH, Dagenais N, Christensen SK, Nguyen JT, Chory J, Harrison MJ, Weigel D. Activation tagging of the floral inducer FT. Science 1999;286:1962-5.

33. Kempin SA, Savidge B, Yanofsky MF. Molecular basis of the cauliflower phenotype in Arabidopsis. Science. 1995;267:522-5.

34. Kim SL, Lee SY, Kim HJ, Nam HG, An GH. OsMADS51 is a short-day flowering promoter that functions upstream of Ehd1, OsMADS14, and Hd3a(1[W][OA]). Plant Physiol. 2007a; 145:1484-94.

35. Kim WY, Fujiwara S, Suh SS, Kim J, Kim Y, Han LQ, David K, Putterill J, Nam HG, Somers DE. ZEITLUPE is a circadian photoreceptor stabilized by GIGANTEA in blue light. Nature. 2007b;449:356-60.

36. Kobayashi Y, Weigel D. Move on up, it's time for changemobile signals controlling photoperiod-dependent flowering. Genes Dev. 2007;21:2371-84.

37. Kobayashi Y, Kaya H, Goto K, Iwabuchi M, Araki T. A pair of related genes with antagonistic roles in mediating flowering signals. Science. 1999;286:1960-2.

38. Kojima S, Takahashi Y, Kobayashi Y, Monna L, Sasaki T, Araki T, Yano M. Hd3a, a rice ortholog of the Arabidopsis FT gene, promotes transition to flowering downstream of Hd1 under shortday conditions. Plant Cell Physiol. 2002;43:1096-105.

39. Komiya R, Ikegami A, Tamaki S, Yokoi S, Shimamoto K. Hd3a and RFT1 are essential for flowering in rice. Development. 2008;135:767-74.

40. Kramer A, Feilner T, Possling A, Radchuk V, Weschke W, Burkle L, Kersten B. Identification of barley CK2 alpha targets by using the protein microarray technology. Phytochemistry. 2004;65:1777-84.

41. Kyozuka J, Kobayashi T, Morita M, Shimamoto K. Spatially and temporally regulated expression of rice MADS box genes with similarity to Arabidopsis class A, B and C genes. Plant Cell Physiol. 2000;41:710-8.

42. Laubinger S, Marchal V, Gentilhomme J, Wenkel S, Adrian J, Jang S, Kulajta C, Braun H, Coupland G, Hoecker U. Arabidopsis SPA proteins regulate photoperiodic flowering and interact with the floral inducer CONSTANS to regulate its stability. Development. 2006;133:3213-22.

43. Lee $S$, An G. Diversified mechanisms for regulating flowering time in a short-day plant rice. J Plant Biol. 2007;50:241-8.

44. Lee SY, Kim J, Han JJ, Han MJ, An GH. Functional analyses of the flowering time gene OsMADS50, the putative SUPPRESSOR OFOVEREXPRESSION OFCO 1/AGAMOUS-LIKE 20 (SOC1/ AGL20) ortholog in rice. Plant J. 2004;38:754-64.

45. Li C, Dobcovsky J Wheat FT protein regulates VRN1 transcription through interactions with FDL2. Plant J. 2008. doi:10.1111/ j.1365-313X.2008.03526.x

46. Lin HX, Yamamoto T, Sasaki T, Yano M. Characterization and detection of epistatic interactions of 3 QTLs, Hd1, Hd2, and Hd3, controlling heading date in rice using nearly isogenic lines. Theor Appl Genet. 2000;101:1021-8.

47. Lin MK, Belanger H, Lee YJ, Varkonyi-Gasic E, Taoka KI, Miura E, Xoconostle-Cazares B, Gendler K, Jorgensene RA, Phinney B, Lough TJ, Lucas WJ. FLOWERING LOCUS T protein may act as the long-distance florigenic signal in the cucurbits. Plant Cell. 2007;19:1488-506.

48. Liu C, Chen H, Er HL, Soo HM, Kumar PP, Han JH, Liou YC, $\mathrm{Yu}$ H. Direct interaction of AGL24 and SOC1 integrates 
flowering signals in Arabidopsis. Development. 2008a;135: 1481-91.

49. Liu LJ, Zhang YC, Li QH, Sang Y, Mao J, Lian HL, Wang L, Yan HQ. COP1-mediated ubiquitination of CONSTANS is implicated in cryptochrome regulation of flowering in Arabidopsis. Plant Cell. 2008b;20:292-306.

50. Locke JCW, Kozma-Bognar L, Gould PD, Feher B, Kevei E, Nagy F, Turner MS, Hall A, Millar AJ. Experimental validation of a predicted feedback loop in the multi-oscillator clock of Arabidopsis thaliana. Mol Syst Biol. 2006;2:59.

51. Mandel MA, Gustafson-Brown C, Savidge B, Yanofsky MF. Molecular characterization of the Arabidopsis floral homeotic gene APETALA1. Nature. 1992;360:273-7.

52. Mathieu J, Warthmann N, Küttner F, Schmid M. Export of FT protein from phloem companion cells is sufficient for floral induction in Arabidopsis. Curr Biol. 2007;17:1055-60.

53. Michaels SD, Himelblau E, Kim SY, Schomburg FM, Amasino RM. Integration of flowering signals in winter-annual Arabidopsis. Plant Physiol. 2005;137:149-56.

54. Mizoguchi T, Wright L, Fujiwara S, Cremer F, Lee K, Onouchi H, Mouradov A, Fowler S, Kamada H, Putterill J, Coupland G. Distinct roles of GIGANTEA in promoting flowering and regulating circadian rhythms in Arabidopsis. Plant Cell. 2005; 17:2255-70.

55. Monna L, Lin HX, Kojima S, Sasaki T, Yano M. Genetic dissection of a genomic region for a quantitative trait locus, $\mathrm{Hd} 3$, into two loci, Hd3a and Hd3b, controlling heading date in rice. Theor Appl Genet. 2002;104:772-8.

56. Murai K, Miyamae M, Kato H, Takumi S, Ogihara Y. WAP1, a wheat APETALA1 homolog, plays a central role in the phase transition from vegetative to reproductive growth. Plant Cell Physiol. 2003;44:1255-65.

57. Murakami M, Tago Y, Yamashino T, Mizuno T. Comparative overviews of clock-associated genes of Arabidopsis thaliana and Oryza sativa. Plant Cell Physiol. 2007;48:110-21.

58. Muszynski MG, Dam T, Li B, Shirbroun DM, Hou ZL, Bruggemann E, Archibald R, Ananiev EV, Danilevskaya ON. Delayed flowering1 encodes a basic leucine zipper protein that mediates floral inductive signals at the shoot apex in maize. Plant Physiol. 2006;142:1523-36.

59. Nakagawa M, Shimamoto K, Kyozuka J. Overexpression of RCN1 and RCN2, rice TERMINAL FLOWER 1/CENTRORADIALIS homologs, confers delay of phase transition and altered panicle morphology in rice. Plant J. 2002;29:743-50.

60. Nijhawan A, Jain M, Tyagi AK, Khurana JP. Genomic survey and gene expression analysis of the basic leucine zipper transcription factor family in rice. Plant Physiol. 2008;146:33350 .

61. Niwa $\mathrm{Y}$, Ito $\mathrm{S}$, Nakamichi $\mathrm{N}$, Mizoguchi $\mathrm{T}$, Niinuma $\mathrm{K}$, Yamashino T, Mizuno T. Genetic linkages of the circadian clock-associated genes, TOC1, CCA1 and LHY, in the photoperiodic control of flowering time in Arabidopsis thaliana. Plant Cell Physiol. 2007;48:925-37.

62. Page T, Macknight R, Yang CH, Dean C. Genetic interactions of the Arabidopsis flowering time gene FCA, with genes regulating floral initiation. Plant J. 1999;17:231-9.

63. Portoles S, Mas P. Altered oscillator function affects clock resonance and is responsible for the reduced day-length sensitivity of CKB4 overexpressing plants. Plant J. 2007; 51:966-77.

64. Riera M, Figueras M, Lopez C, Goday A, Pages M. Protein kinase CK2 modulates developmental functions of the abscisic acid responsive protein Rab17 from maize. Proc Natl Acad Sci USA. 2004;101:9879-84.

65. Samach A, Onouchi H, Gold SE, Ditta GS, Schwarz-Sommer Z, Yanofsky MF, Coupland G. Distinct roles of CONSTANS target genes in reproductive development of Arabidopsis. Science. 2000;288:1613-6.

66. Sawa M, Nusinow DA, Kay SA, Imaizumi T. FKF1 and GIGANTEA complex formation is required for day-length measurement in Arabidopsis. Science. 2007;318:261-5.

67. Shitsukawa N, Ikari C, Shimada S, Kitagawa S, SakaMoto K, Saito H, Ryuto H, Fukunishi N, Abe T, Takumi S, Nasuda S, Murai K. The einkorn wheat (Triticum monococcum) mutant, maintained vegetative phase, is caused by a deletion in the VRN1 gene. Genes Genet Syst. 2007;82:167-70.

68. Stemmer C, Schwander A, Bauw G, Fojan P, Grasser KD. Protein kinase CK2 differentially phosphorylates maize chromosomal high mobility group B (HMGB) proteins modulating their stability and DNA interactions. J Biol Chem. 2002;277:1092-8.

69. Sugano S, Andronis C, Green RM, Wang ZY, Tobin EM. Protein kinase CK2 interacts with and phosphorylates the Arabidopsis circadian clock-associated 1 protein. Proc Natl Acad Sci USA. 1998;95:11020-5.

70. Sugano S, Andronis C, Ong MS, Green RM, Tobin EM. The protein kinase CK2 is involved in regulation of Circadian rhythms in Arabidopsis. Proc Natl Acad Sci USA. 1999;96:12362-6.

71. Takada S, Goto K. TERMINAL FLOWER2, an Arabidopsis homolog of HETEROCHROMATIN PROTEIN1, counteracts the activation of FLOWERING LOCUS T by CONSTANS in the vascular tissues of leaves to regulate flowering time. Plant Cell. 2003;15:2856-65.

72. Takahashi Y, Shomura A, Sasaki T, Yano M. Hd6, a rice quantitative trait locus involved in photoperiod sensitivity, encodes the alpha subunit of protein kinase CK2. Proc Natl Acad Sci USA. 2001;98:7922-7.

73. Takano M, Inagaki N, Xie XZ, Yuzurihara N, Hihara F, Ishizuka T, Yano M, Nishimura M, Miyao A, Hirochika H, Shinomura T. Distinct and cooperative functions of phytochromes A, B, and C in the control of deetiolation and flowering in rice. Plant Cell. 2005; 17:3311-25.

74. Tamaki S, Matsuo S, Wong HL, Yokoi S, Shimamoto K. Hd3a protein is a mobile flowering signal in rice. Science. 2007; 316:1033-6.

75. Teper-Bamnolker P, Samach A. The flowering integrator FT regulates SEPALLATA3 and FRUITFULL accumulation in Arabidopsis leaves. Plant Cell. 2005;17:2661-75.

76. Wigge PA, Kim MC, Jaeger KE, Busch W, Schmid M, Lohmann $\mathrm{JU}$, Weigel D. Integration of spatial and temporal information during floral induction in Arabidopsis. Science. 2005;309:1056-9.

77. Xue W, Xing Y, Weng X, Zhao Y, Tang W, Wang L, Zhou H, Yu $\mathrm{S}, \mathrm{Xu} \mathrm{C}$, Li X, Zhang Q. Natural variation in Ghd7 is an important regulator of heading date and yield potential in rice. Nat Genet. 2008;40:761-7.

78. Yamaguchi A, Kobayashi Y, Goto K, Abe M, Araki T. TWIN SISTER OF FT (TSF) acts as a floral pathway integrator redundantly with FT. Plant Cell Physiol. 2005;46:1175-89.

79. Yamamoto T, Lin HX, Sasaki T, Yano M. Identification of heading date quantitative trait locus Hd6 and characterization of its epistatic interactions with $\mathrm{Hd} 2$ in rice using advanced backcross progeny. Genetics. 2000;154:885-91.

80. Yamamoto T, Kuboki Y, Lin SY, Sasaki T, Yano M. Fine mapping of quantitative trait loci Hd-1, Hd-2 and Hd-3, controlling heading date of rice, as single Mendelian factors. Theor Appl Genet. 1998;97:37-44.

81. Yan L, Loukoianov A, Tranquilli G, Helguera M, Fahima T, Dubcovsky J. Positional cloning of the wheat vernalization gene VRN1. Proc Natl Acad Sci USA. 2003;100:6263-8.

82. Yan L, Fu D, Li C, Blechl A, Tranquilli G, Bonafede M, Sanchez A, Valarik M, Yasuda S, Dubcovsky J. The wheat and barley vernalization gene VRN3 is an orthologue of FT. Proc Natl Acad Sci USA. 2006;103:19581-6. 
83. Yano M, Kojima S, Takahashi Y, Lin HX, Sasaki T. Genetic control of flowering time in rice, a short-day plant. Plant Physiol. 2001;127:1425-9.

84. Yano M, Katayose Y, Ashikari M, Yamanouchi U, Monna L, Fuse T, Baba T, Yamamoto K, Umehara Y, Nagamura Y, Sasaki T. Hd1, a major photoperiod sensitivity quantitative trait locus in rice, is closely related to the Arabidopsis flowering time gene CONSTANS. Plant Cell. 2000;12:2473-83.
85. Zeevaart JAD. Florigen coming of age after 70 years. Plant Cell. 2006;18:1783-9.

86. Zeilinger MN, Farre EM, Taylor SR, Kay SA, Doyle FJ. A novel computational model of the circadian clock in Arabidopsis that incorporates PRR7 and PRR9. Mol Syst Biol. 2006;2:58.

87. Zhang SH, Hu WJ, Wang LP, Lin CF, Cong B, Sun CR, Luo D. TFL1/CEN-like genes control intercalary meristem activity and phase transition in rice. Plant Science. 2005;168:1393-408. 